\title{
Design and Application of a Remote Electronic Communication Teaching System in a Network Environment
}

\author{
https://doi.org/10.3991/ijet.v13i04.8480 \\ Wei Zhai \\ Xi'an Aeronautical University, Xi'an, China \\ $2587842805 @$ gq. com
}

\begin{abstract}
With the design and application of remote teaching system as the research target, this study uses the research methods of literature research method, website investigation method and system development to make a detailed research on the theory of remote collaborative learning and electronic communication technology. On the basis of web-based teaching platform of remote education, this study puts forward a long-remote collaborative teaching system of electronic communication along with the network environment, and designs the function modules of the system in detail, in which the communication effect of electronic communication technology on group members and teachers' creation of collaborative learning situations are fully considered. Finally, the practicality and validity of the system are verified by the realization of the system, which provides a wider development space for the remote teaching system.
\end{abstract}

Keywords-electronic communication; remote education; long-remote collaborative learning; remote teaching system

\section{Introduction}

Modern remote education is a new form of education developed on the basis of rapid development of computer, network and electronic communication technology and boasts the characteristics of space-time separation, which can solve the shortage of educational resources, realize resource sharing [1] and meet the needs of life-long learning. With the deepening of education and teaching reform, the original remote teaching system based on teachers' teaching and students' independent learning cannot solve the lonely psychological state when students study independently, which is not conducive to the communication between teachers and students, and hardly guarantees the students' learning enthusiasm and learning quality. Therefore, more and more people begin to make use of all kinds of information technologies to construct a wellstructured and powerful long-remote collaborative teaching system, and change the long-remote teaching mode from "teaching" to "learning" -oriented teaching mode [2]. Long-remote collaborative learning is a new teaching form based on the network 
teaching platform, which develops as the learners as the center in line with the needs of the times. Since the 1990s, nearly 100 colleges and universities in China have set up online teaching platforms and built a plenty of online teaching resources. The research emphases on teaching platform vary over the change of the times. With the continuous introduction of new technologies, network long-remote collaborative learning researches have been carried out for nearly 15 years and have obtained some achievements, where long-remote collaborative learning project (TCSCL) and Moodle network teaching platform are representatives of long-remote collaborative learning platforms focusing on "learning". The advent and development of electronic communication technology make the communication between teachers and students in remote collaborative learning more convenient and faster [3]. However, at present, the application of electronic communication technology in remote collaborative learning is still lacking in the design of learning analysis and task management functions.

In order to solve the above problems, based on the research and analysis of remote collaborative learning and electronic communication technology and the existing network teaching platform and resources, this study puts forward a remote collaborative teaching system of electronic communication in the network environment, and effectively integrates electronic communication into the remote teaching platform through the design and realization of the system, building a bridge for teachers and students to communicate with each other and providing a new direction for the development of remote teaching system.

\section{Related Theories and Technologies}

\subsection{Modern remote education}

Modern remote education is a form of education based on computer and network technology. It has the characteristics of resource sharing, autonomous flexibility and so on. With advantages incomparable to traditional teaching, it provides learners with a way of autonomous learning at anytime and anywhere to meet the needs of lifelong learning. However, with the promotion of education and teaching reform, the existing remote teaching platform is of the traditional teaching mode, namely teacher-based teaching style, in which there is less communication and cooperation between teachers and students and among learners, and most of the learners are in independent learning state, thus it is difficult to arouse their enthusiasm for learning [4] and the teaching effect is not good enough.

\subsection{Remote collaborative learning in the network environment}

Collaborative learning is a strategy of organizing students for learning in the form of groups or groups based on constructivism, humanism and the theory of cultural and historical development [5], so as to realize the learning goal of common learning and promoting development. 
Remote collaborative learning is a learning method based on Internet technology and resources. Learners and teachers can communicate and contact with each other through remote teaching platform, thus completing the task of collaborative learning. Because remote collaborative learners usually come from different regions, and their culture, technical ability, means of obtaining resources and personality are different, the process control of remote collaborative learning will directly affect the learning effect. Therefore, the process of group division and cooperation should be reasonably controlled. Figure 1 shows the process control flow of remote collaborative learning [6]. This study summarizes the flow into seven dimensions, which are collaborative interaction, collaborative learning task, collaborative scope, collaborative learning environment, collaborative learning process evaluation, collaborative learning environment function control and support collaborative learning method control.

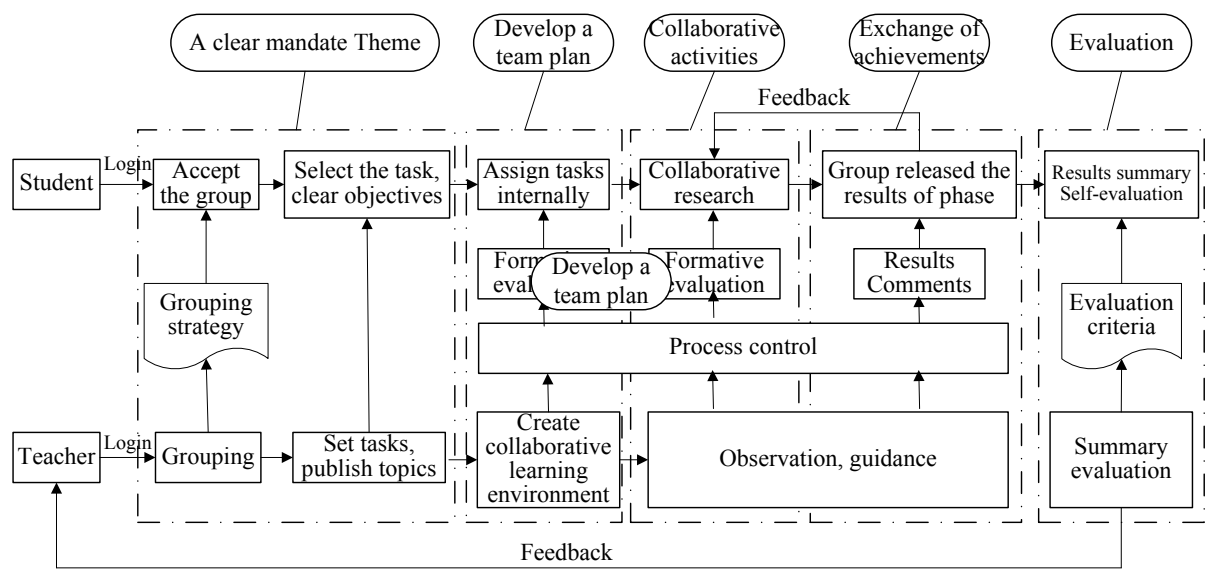

Fig. 1. Remote collaborative learning process control process

\subsection{Researches on electronic communication technology in remote cooperative learning}

Integration of electronic communication technology and teaching resources: Electronic communication technology is realized based on TCP / IP network protocol. With the development of electronic communication technology, its functions have been developed from simple characters and symbols to high-level information exchange such as video and shared files [7]. People are familiar with such electronic communication systems as QQ, MSN and ICQ and. With the continuous maturity and development of electronic communication technology, it has been widely used in various fields, and has become more and more mature in the field of education. The real-time interaction and communication function of electronic communication technology can better serve the communication among group members and teachers in remote collaborative teaching. However, through the investigation of remote teaching platform both at home and abroad, it is found that currently electronic communication clients and teaching resource platform are mostly designed and applied independently. 
The corresponding electronic communication system that teachers recommend for students serve as a platform for teacher-student communication, which is easy to cause students immersed in chatting, thus reducing the efficiency of learning. So if the electronic communication technology and teaching resources are integrated, namely, embedding electronic communication system in the teaching platform [8] to provide a systematic remote collaborative learning environment for students, it will be easier for the students to use the platform of teaching resources for discuss in terms of teaching content, thus improving learning efficiency.

Remote collaborative learning mode based on electronic communication technology: In order to realize the integration of electronic communication system into the teaching platform, which enables the combination of the student login platform with the login electronic communication system and thus the electronic communication system can be used to transmit the teaching materials and data among students and between students and teachers, this study puts forward a long-distance collaborative learning mode of electronic communication in network environment, and summarizes it into the following eight modes: task-driven mode, personality training mode, discussion and inquiry learning mode, social role learning mode, teacher-student communication learning mode, situational cognitive learning mode, experience sharing learning mode and resource acquisition learning mode.

Figure 2 shows the information interaction between electronic communication systems and collaborative learning components.

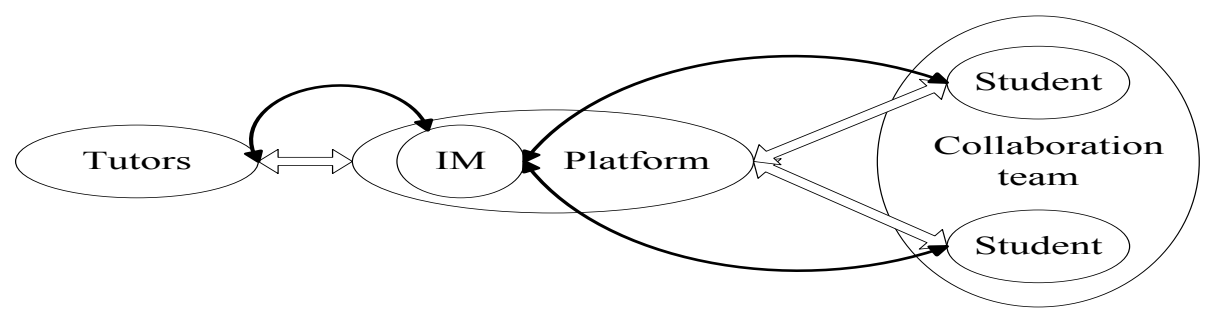

Fig. 2. Interaction between electronic communication systems and collaborative learning components

\section{Design and Application of Electronic Communication Remote Collaborative Teaching System Based on Network Environment}

\subsection{Design of electronic communication remote collaborative teaching system based on network environment}

In order to enable the students to learn and communicate in the collaborative learning environment created by teachers and realize the functions of remote collaborative learning, the system will embed the electronic communication system in the network learning platform. Figure 3 shows the system architecture, which uses the develop- 
ment mode of MVC three-tier architecture divided into three parts: view layer, model layer and control layer.

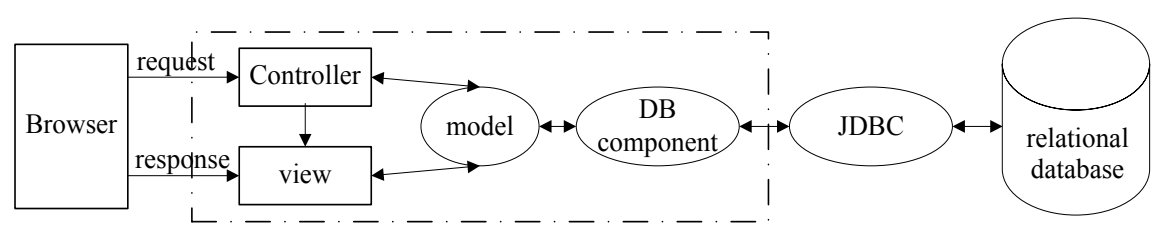

Fig. 3. System architecture

\subsection{Design of system modules}

By analyzing the functions and requirements of the system, the system mainly contains three functional modules and one database module. The main functions of each module are as follows:

Student module: The main function of the student user module is to receive and send information related to the teaching activity as shown in Figure 4 for the structure diagram of the student module. Specifically, it includes: 1) message notification, 2) bulletin board, 3) topic selection, selecting task topics arranged by teachers; 4) discussion: students can discuss with the group members according to the selected topic. During discussion, it can display the names, speech contents and other information of all group members, which can also be rated and evaluated; 5) statistical analysis, the system can conduct statistical analysis based on students' participation and performance, and students can reflect and self-motivate which seeing statistics; 6) plan arrangement, it's convenient to make a plan and arrangement for task subject study according to their own situation for teachers and members of the same group to guide and determine time for discussion and study according to arrangement; 7) setting information, setting personal information is not only convenient for group members to communicate with each other, but also to establish good interpersonal relationship through mutual communication.

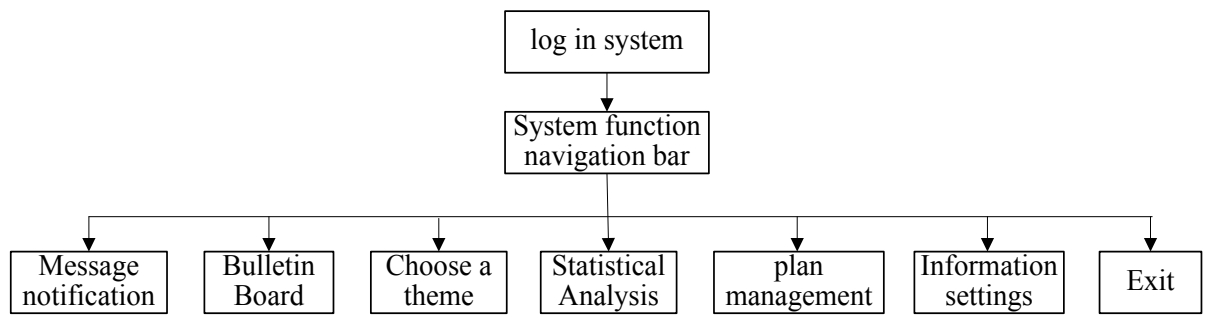

Fig. 4. Student module structure diagram

Teacher module: In the remote collaborative learning of electronic communication based on network environment, teachers undertake more responsibilities and tasks than ever before. Teachers need to design learning situations and tasks, provide 
reference materials for learners, guide and evaluate the contents of group discussion, etc. The structure of teacher module designed according to the role of teachers in the remote collaborative learning mainly includes: 1) discussion module: participate in the discussion of the task topic of the students, and provide guidance and evaluation timely in accordance with the contents of the students' discussion, so as to improve students' enthusiasm of learning as well as their efficiency of learning; 2) statistical analysis module: it is divided into three parts: the first part is basic information statistics, mainly including student information statistics, discussion subject history record, planning arrangement history record, subject concern degree, student discussion activity degree, teacher participation situation, professional classification statistics and so on; the second part is information exchange management, including arranging students' learning activities plan, arranging discussion topics, checking and sending message notifications, providing relevant learning resources to students, and guiding students to learn; the third part is the basic setting, including the modification and maintenance of personal information and the function of grouping the group information of the students. The function diagram structure is basically similar to the student module, and it is not listed in detail here.

System administrator module: The system administrator is mainly responsible for verifying the validity of the logged-in users, providing the corresponding interface according to the user authority, and completing the group information and system initialization setting at the same time. Figure 5 shows the system management function profess.

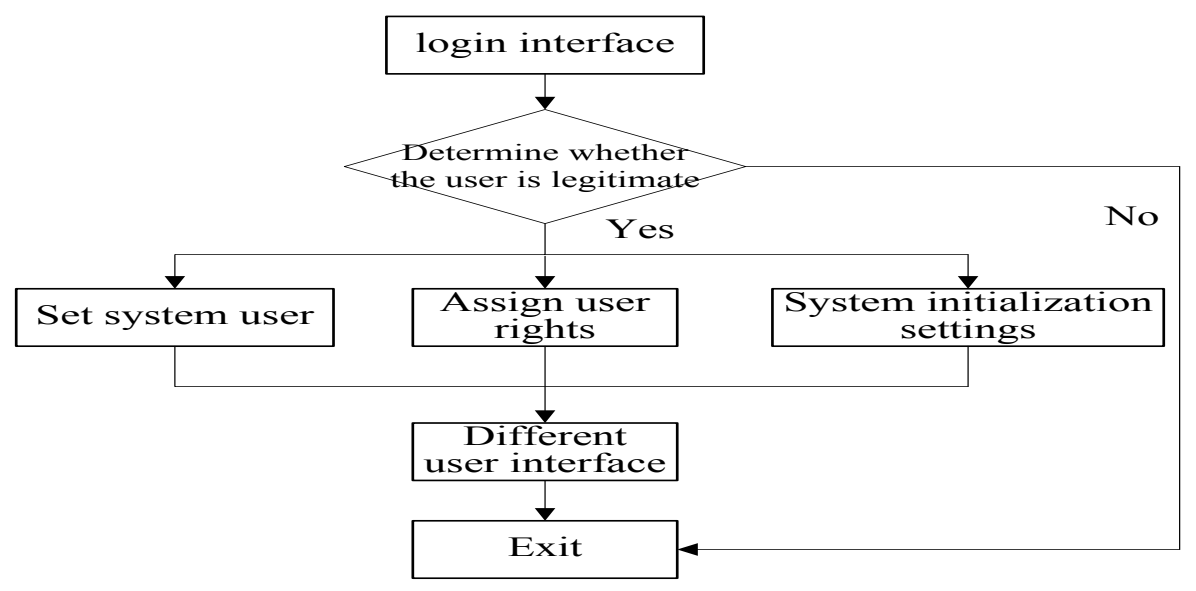

Fig. 5. System management function process

Database design: This part is the core of the whole system. In order to realize the function of each module, the following data table is required: recorded module table of collaborative activities, group information table, internal short messages list, plan \& schedule tables, task topics list, event \& task selection table and bulletin board table, and all the modules of data should be stored a database table designed in ad- 
vance for the system call. This system adopts the JDBC database connection technology for the database programming.

\subsection{Realization of the system module function}

Realization of the login module: Figure 6 shows the login interface of the system. After the user inputs the user name, password and verification code according to the prompts, the user can log in to the interface of his / her authority. The main function of the module is to ensure the security of the system. If the user inputs a wrong user name or password, the system will prompt to re-login or register.

Collaborative learning discussion space module: After logging in successfully, the user enters the corresponding interface that belongs to his or her own authority, and selects the corresponding function to enter the sub-interface according to the prompt. This study only takes the collaborative space discussion module as an example to illustrate the implementation situation of the system interface.

Figure 7 shows the function interface of sending and receiving information of the group members in the collaborative learning discussion space module, which is also the most important part of the remote collaborative learning of electronic communication in the network environment. The realization of the function can solve the lonely psychology of students in studying alone, and enhance the enthusiasm and inner experience of learning through the discussion among the members. The main function of this interface is to send and receive discussion information among group members. At the same time, you can see the online and offline status and scoring status of all members in the group. At the same time, there is a brief description for group tasks below the interface, so as to guide learners to study.

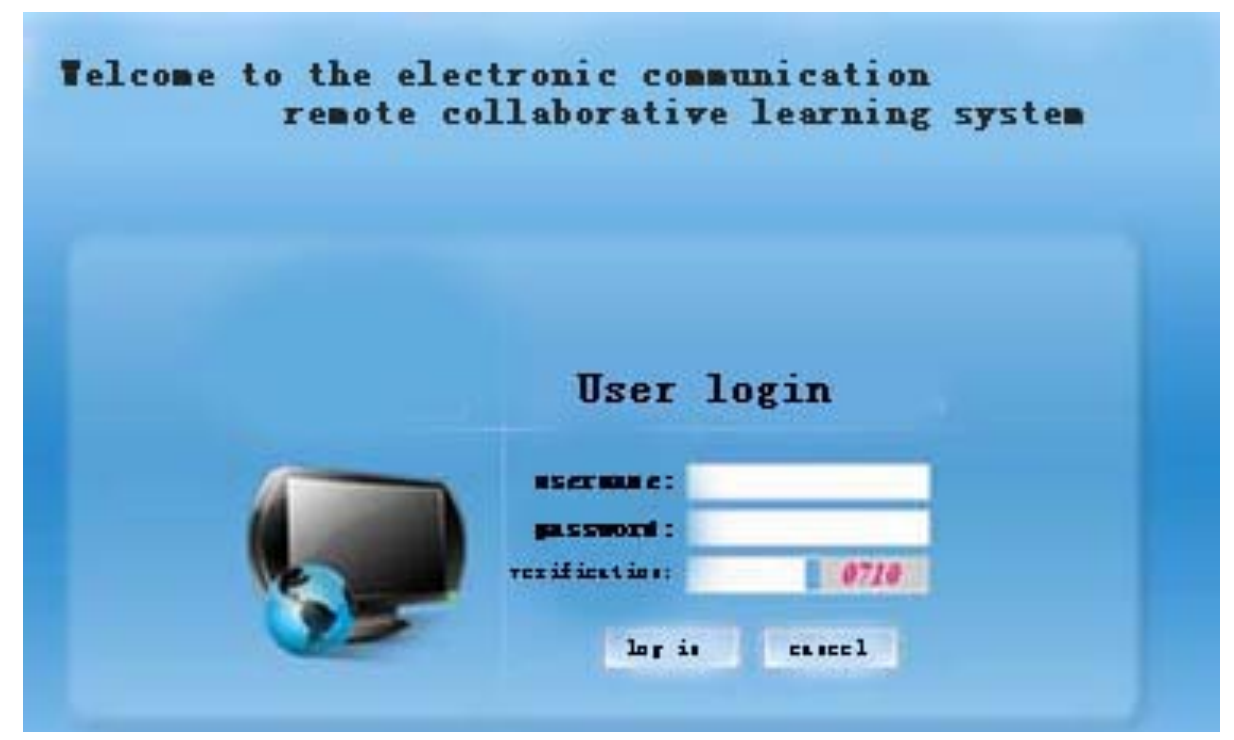

Fig. 6. System login interface 


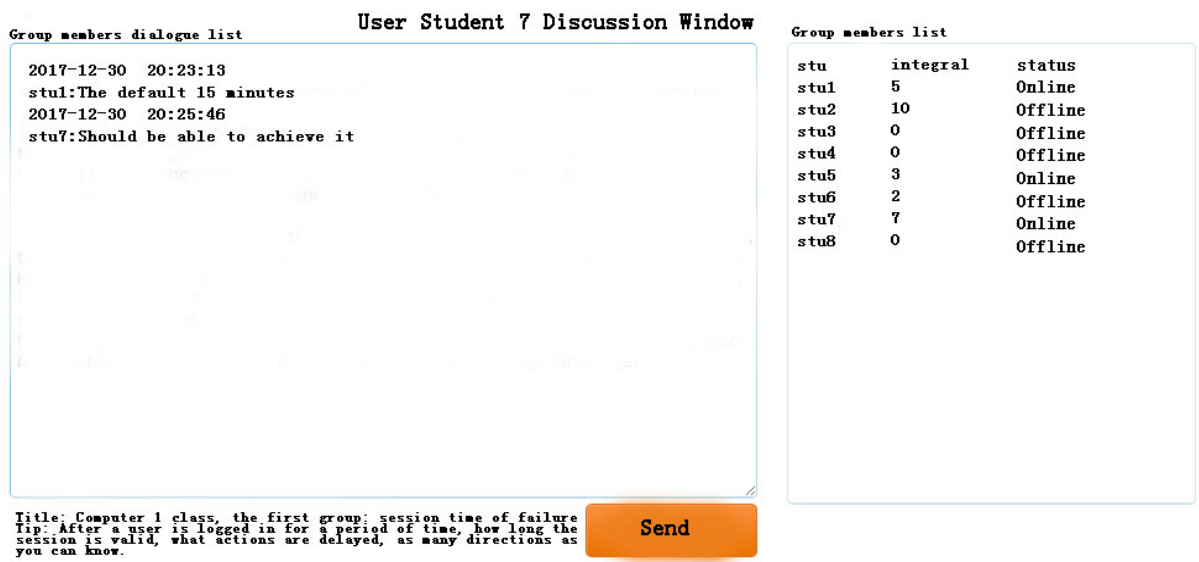

Fig. 7. Group members sending and receiving information function interface

\section{Conclusions}

This study takes the application of electronic communication technology in remote education as the research object and puts forward a remote collaborative teaching system of electronic communication in network environment after an analysis and study on the basis of looking up domestic and foreign references and visiting domestic and foreign remote education websites. The concrete research conclusions are as follows:

Through the analysis and research of the modern remote teaching system, it is found that the present remote teaching system has such problems as the single teaching mode, which is unfavorable for communication between teachers and students, the lonely learning psychology of students, and failure to guarantee the teaching effect.

Through the analysis and research of remote collaborative learning and electronic communication technology, a remote collaborative learning mode based on electronic communication technology is proposed, and the importance of embedding electronic communication system into the remote collaborative learning platform is analyzed.

Based on the existing remote teaching system and educational resources, a remote collaborative teaching system of electronic communication in network environment is designed and realized, which provides a wider space for the development of remote teaching.

\section{$5 \quad$ References}

[1] Kompf, M. (2005). Information and communications technology (ICT) and the seduction of knowledge, teaching, and learning: what lies ahead for education. Curriculum Inquiry, 35(2), 213-234. https://doi.org/10.1111/j.1467-873X.2005.00325.x 
[2] Deaney, R., Ruthven, K., Hennessy, S. (2003). Pupil perspectives on the contribution of information and communication technology to teaching and learning in the secondary school. Research Papers in Education, 18(2), 141-165. https://doi.org/10.1080/0267152 032000081913

[3] Torgerson, C.J., Elbourne, D. (2010). A systematic review and meta-analysis of the effectiveness of information and communication technology (ICT) on the teaching of spelling. Journal of Research in Reading, 25(2), 129-143. https://doi.org/10.1111/1467-9817.00164

[4] Trentin, G. (2006). The Xanadu project: training faculty in the use of information and communication technology for university teaching. Journal of Computer Assisted Learning, 22(3), 182-196. https://doi.org/10.1111/j.1365-2729.2006.00168.x

[5] Blaye, A., Light, P., Rubtsov, V. (1992). Collaborative learning at the computer; how social processes 'interface' with human-computer interaction. European Journal of Psychology of Education, 7(4), 257-267. https://doi.org/10.1007/BF03172892

[6] Tobagi, F. A. (1995). Distance learning with digital video. IEEE Multimedia, 2(1), 90-93. https://doi.org/10.1109/93.368609

[7] Colbert, M., Voglimacci, C., Finkelstein, F. (1995). Live, audio-visual communication systems for distance learning: experience, heuristics, and isdn. Behaviour \& Information Technology, 14(5), 267-288. https://doi.org/10.1080/01449299508914647

[8] Sharda, R., Romano, N.C., Lucca, J.A., Weiser, M., Scheets, G., Chung, J.M. (2004). Foundation for the study of computer-supported collaborative learning requiring immersive presence. Journal of Management Information Systems, 20(4), 31-64. https://doi.org/10.1080/07421222.2004.11045780

\section{Authors}

Wei Zhai received the B.E. degree in electronic information engineering from Xi'an University of Technology, Xi'an, China, in 2003, the M.E. degree in communications engineering from Xi'an Jiaotong University, Xi'an, China, in 2012.Since 2003, she has been on the faculty of Xi'an Aeronautical University. She is manly engaged in the research of electronic and communication.

Article submitted 20 February 2018. Final acceptance 25 March 2018. Final version published as submitted by the author. 